\title{
Household perceptions of climate change and preferences for mitigation action: the case of the Carbon Pollution Reduction Scheme in Australia
}

\author{
Sonia Akter • Jeff Bennett
}

Received: 23 June 2009 / Accepted: 4 January 2011 / Published online: 26 February 2011

(C) The Author(s) 2011. This article is published with open access at Springerlink.com

\begin{abstract}
The study aims to reveal Australian households' perceptions of climate change and their preferences for mitigation action. A web-based survey was conducted in November 2008 in which over 600 households from the state of New South Wales were asked for their willingness to bear extra household expenditure to support the 'Carbon Pollution Reduction Scheme', an emissions trading scheme proposed by the Australian government. The results of the study can be summarized in four key findings. First, respondents' willingness to pay for climate change mitigation is significantly influenced by their beliefs of future temperature rise. Support for the policy increased at a decreasing rate as the perceived temperature change rose. Second, perceptions of policy failure have a significant negative impact on respondents' support for the proposed mitigation measure. The higher the perceived likelihood that the measure would not deliver any outcome, the lower was the likelihood that respondents would support the policy. Third, respondent preferences for the proposed policy are influenced by the possibility of reaching a global agreement on emissions reduction. Sample respondents stated significantly higher values for the policy when the biggest polluting countries implement a similar scheme. Finally, respondents' willingness to take action against climate change, both at the national and household level, is found to be influenced by their level of mass-media exposure. Particularly, those respondents who watched 'An Inconvenient Truth' were significantly more likely to act for climate change mitigation than others.
\end{abstract}

\footnotetext{
S. Akter $(\bowtie) \cdot$ J. Bennett

Crawford School of Economics and Government (Building 132),

The Australian National University,

Canberra, ACT 0200, Australia

e-mail: sonia.akter@anu.edu.au
} 


\section{Introduction}

Australia's annual average temperatures are projected to increase by $2^{\circ} \mathrm{C}$ above 1990 levels by 2030, and $5^{\circ} \mathrm{C}$ by 2100 (Garnaut 2008). As a result, precipitation is likely to decrease in the southeast and increase in the northwest region (CSIRO 2007). Australia's coastlines are expected to experience a rise in sea level of about 8 to $88 \mathrm{~cm}$ potentially leading to coastal erosion and inundation (CSIRO 2007). Such changes are projected to have negative impacts on Australia by affecting the environment, economy, and public health. Among the most notable predicted impacts are (1) $92 \%$ decline in agricultural production in the Marry-Darling basin, (2) damage to the coastal infrastructure and settlements, (3) catastrophic destruction of the iconic Great Barrier Reef and (4) over 4000 additional heat-related deaths in the Northeastern Australia (Garnaut 2008).

Given these projections, climate change mitigation has been a dominant theme in Australia's public policy debate over the past 3 years. In December 2007, the Australian Government ratified the Kyoto Protocol as a commitment to curbing climate change. Subsequently, the government has proposed a national emissions trading scheme, known as the Carbon Pollution Reduction Scheme (CPRS) to fulfil the Kyoto protocol obligations and beyond. The CPRS is a market-based response to climate change mitigation based on a 'cap and trade' model.

A significant debate surrounds the implication of the CPRS for the Australian economy. The first concern arises from the 'global public good' aspect of climate change policy. Any effective mitigation of climate change requires all actual and potential emitters to comply with a similar set of emission reduction objectives (Karl and Trenberth 2003). However, reaching a legally binding multilateral agreement on a common emissions reductions target has been the key challenge facing the global political leaders in the current decade. The Copenhagen climate summit held in December 2009 failed to reach such an agreement. The Copenhagen Accord which was signed by 107 countries calls for limiting the rise in global average temperatures to no more than $2^{\circ} \mathrm{C}$ beyond pre-industrial levels by 2100 . Under the Accord, two major green house gas (GHG) emitting countries-China, India-have committed to reduce their emissions intensity (emission as a percentage of gross domestic product) between 20 to $40 \%$ of 2005 level by 2020, while the USA, the second largest GHG emitting country in 2007 (UNFCCC 2008), has promised to reduce $17 \%$ of 2005 level GHG emissions by 2020. These targets are purely voluntary in nature and are inadequate to achieve the Accord's objective of limiting the global average temperature rise to $2^{\circ} \mathrm{C}$ by 2100 .

Given that the world has failed to reach a legally binding multilateral framework for climate change mitigation, the unilateral implementation of the CPRS in Australia is not expected to make any significant contribution to preventing climate change. Although Australia's per capita GHG emissions are the highest among the developed nations (Garnaut 2008), the total pollution contribution of the country in the global context is relatively low. In 2007, Australia emitted a total of 597 million tonnes of carbon dioxide $\left(\mathrm{CO}_{2}\right)$ equivalent into the earth's biosphere (Department of Climate Change and Energy Efficiency 2010). This is less than 2\% of total world emissions. Given this relatively low level of GHG emissions in the global context, Australia's participation in the global climate change mitigation effort can be viewed as a way of showing that the country is not seeking a 'free-ride' (Department of Climate Change and Energy Efficiency 2008). 
In this context, the current study aims to explore how the Australian community perceives climate change impacts and the proposed mitigation measure. More specifically, we seek to investigate how much sacrifice the Australian society is willing to make in monetary term to support a mitigation policy that is surrounded by uncertainty from three different sources, namely climate change scale, policy effectiveness and global co-operation. A contingent valuation (CV) study was carried out in Sydney, the state capital of New South Wales, in November 2008. During the survey, the sample households were asked for their preferences to bear extra household expenses per month to support the CPRS. Further, respondents were asked if they had undertaken any initiative at the household level to contribute towards climate change mitigation efforts by reducing their consumption of carbon intensive goods, such as electricity and transportation. Responses to these questions were analyzed using multivariate probit regression techniques to identify the determinants of stated preference for climate change mitigation.

Although a number of CV studies investigated individual preferences for climate change mitigation, no studies examine public preferences under the condition of multiple sources of uncertainty. Further, this is the first CV study in the climate change arena that involves a public survey to estimate the value that households attach to a proposed national emissions trading scheme. Existing studies were undertaken by creating a hypothetical policy scenario which may result in hypothetical bias. A survey that involves an actual public policy enhances the consequentiality property of the survey and thus provides respondents incentives to reveal their preferences truthfully (Carson and Groves 2007).

The rest of the paper is organised as follows. Section 2 summarizes the relevant literature in this field followed by a description of the survey instrument in Section 3. Section 4 presents respondents' socio-demographic characteristics. Respondents' perceptions of climate change and climate change policy are discussed in Section 5. Section 6 sets out the multivariate regression results. Section 7 provides a discussion of the results and includes concluding remarks.

\section{Literature review}

The CV method is a stated preference technique that has been widely applied over the past 30 years to estimate economic benefits of environmental policy interventions. The method employs public surveys to ask the relevant group of population about their willingness to pay (WTP) to protect an environmental good by constructing a hypothetical market or referendum. In a CV survey, respondent are asked to indicate the maximum amount of money they are willing to sacrifice to receive an improvement in environmental quality. WTP is measured by estimating the compensating surplus - the amount of income paid that leaves the households at the initial level of well-being.

A number of CV studies have addressed the issue of welfare gain from various climate change policy interventions (e.g. Berk and Fovell 1999; Berrens et al. 2004; Cameron 2005; Viscusi and Zeckhauser 2006; Lee and Cameron 2008). Berk and Fovell's (1999) study is one of the first CV studies attempting to estimate the welfare gain associated with climate change mitigation. They used eight different climate change scenarios (four summers and four winters). The findings suggested 
that respondents' WTP is influenced primarily by increases in temperature during the summer scenarios and decreases in precipitation during the winter scenarios. Further, WTP was found to be influenced by respondents' concerns regarding the impact of climate change on the quality of life, wildlife habitats, the economy and what future generations will inherit.

Berrens et al. (2004) investigated the issues of information access and respondent effort in CV surveys. They conducted a web-based survey in the US asking households to state their WTP for ratification of the Kyoto Protocol. The results of the study revealed that respondent effort in acquiring additional information regarding climate change and the Kyoto protocol is positively and significantly related to their WTP. In addition, they showed that respondents' education, political ideology, perceptions of effectiveness of the Kyoto protocol and level of familiarity with the protocol played important roles in determining support for the ratification decision.

Cameron (2005) and Viscusi and Zeckhauser (2006) estimated individual WTP to avoid future climate change using a convenience sample of college students. Both of these studies accounted for the influence of respondents' perceptions of the scale of unmitigated climate change on their decisions to support a climate change policy. Cameron (2005) found individual support for climate change mitigation increases at a decreasing rate with the increase in expected scale of climate change. She also showed that individual WTP varies negatively with the level of climate change scale uncertainty (measured by the variance of respondents' subjectively estimated future temperature increases). Further, she found WTP for climate change mitigation varied significantly across male and female respondents and respondents' level of informedness of climate change. Viscusi and Zeckhauser (2006) showed that the relationship between the expected scale of unmitigated climate change and respondents' WTP for climate change mitigation was positive and linear. Contrary to Cameron's (2005) result, they found that greater scientific uncertainty about the scale of climate change lead to higher support for mitigation policy. Further, they showed that WTP vary substantially depending on respondents' perceptions of the impact of climate change. Respondents who believed climate change would cause significant increases in hurricane activity, were willing to pay more to support the mitigation policy.

Lee and Cameron (2008) conducted a nationwide mail survey to estimate US residents' WTP for climate change mitigation. They showed that residents' WTP is higher when the mitigation costs are shared internationally, rather than being mostly borne by a small group of countries. They also showed that individual WTP varies depending on respondents' perceptions of the severity of climate change impacts. People are willing to pay more if they believed that the harm caused by climate change will be substantial, rather than moderate.

\section{Description of the questionnaire}

Following Cameron (2005) and Viscusi and Zeckhauser (2006), the perceived change in average future temperature was chosen as an indicator of climate change. Respondents were first shown a figure displaying average annual temperature in Australia for the period of 1910 to 2007. They were then presented with a series of 32 different levels of possible changes in annual average temperature ranging from $-5^{\circ} \mathrm{C}$ to 
$+10^{\circ} \mathrm{C}$. Respondents were asked to indicate their best guesses of temperature change in 2100 relative to the current year. 'Best guess' referred to the most likely change in temperatures. Respondents were then asked to indicate a range around their 'best guesses' in the form of high and low guesses where high guess measured the highest possible change and low guess referred to the lowest possible change in temperature.

A numerical probability scale was included to elicit respondents' perceptions of the effectiveness of the CPRS followed by a set of three questions related to best, high and low guess probability of policy success. A verbal probability classification, consistent with the IPCC likelihood scale, was attached to the numerical scale. At this stage, respondents were asked a series of three set of questions. First, two questions were asked to distinguish policy uncertainty arising from lack of scientific knowledge and from lack of global co-operation. Global co-operation was defined as a situation where, in addition to the European Union countries and Australia, at least three major GHG emitting countries i.e. US, China and India, would implement a similar emission reduction scheme by underpinning a national legislation. Second, respondents were asked to state their perceptions of likelihood of the world reaching a global co-operation.

In the valuation part of the questionnaire, respondents were asked two sequential WTP questions. First, they were asked if they would be willing to bear extra household expenses each month on behalf of their households to support the CPRS (hereafter called the 'first WTP question'). Increased prices of goods and services was used as the payment vehicle. This vehicle was deemed to be the most realistic option given the policy context. The vehicle is also considered to be fair as it is based on the polluter's pay principle (Macmillan et al. 1996). However, this vehicle may cause some degree of positive bias as some respondents may say 'Yes' to the offered bid level thinking that they would be able to control their household expenses by adjusting their behavior in the changed price regime.

Eight different bids ranging from AUD $20^{1}$ to AUD 400 per month per household were randomly assigned across the respondents. ${ }^{2}$ They were not given any information about the potential for global co-operation at this stage. Instead, they were advised to keep their perceptions about the likelihood of reaching a broader global consensus about emissions reduction targets in mind when answering the first WTP question. Respondents who said 'No' to the first WTP question were followed up with a second WTP question (hereafter called the 'second WTP question') in which they were asked whether they would be willing to pay the offered bid amount if global co-operation could be achieved.

In addition to these questions, respondents were asked a set of socio-demographic (e.g. occupation, income, household size) and attitudinal questions (e.g. level of concern regarding climate change, relative importance of a climate change mitigation policy, if they believed climate change is caused by human action). A set of questions were included that measured respondents' knowledge and level of familiarity with the scenario and policy context (e.g. whether respondents have heard about the

\footnotetext{
${ }^{1}$ In December 2008, 1 Australian dollar was equivalent to 70 US cents.

${ }^{2}$ These bid amounts were based on responses obtained from an open-ended WTP question asked during the first round focus group. The bid amounts were tested in a second round of focus groups and a pilot survey.
} 
CPRS, Kyoto protocol, IPCC) and their perceptions of the impacts of climate change on Australia and on their households.

\section{The survey and sample characteristics}

A web-based survey was conducted with 634 respondents in Sydney from the third week of November 2008 until the first week of December 2008. Over 17,000 email invitations were sent to a pre-existing sample panel consisting of about 30,000 individuals. About one third of the e-mail invitations were opened. Half of the email recipients who opened the e-mail completed the survey. In total, about 2000 completed questionnaires were received as part of the whole project. About one third of the total responses (634) were collected for this study whereas the rest two thirds of the interviews involved a choice modelling experiment in various split sample treatments.

Table 1 compares the socio-economic characteristics of the 634 sampled households with the regional and national population statistics. A chi-square test of proportions revealed that the differences between the sample and the Sydney population and the Australian population with respect to sex ratio are not statistically significant. However, although the educational attainments of the sample were not found to be significantly different than the Sydney population (chi square $=0.24$, $p=0.97)$, they were significantly different than the educational attainments of the Australian population (chi square $=16.26, p<0.01$ ). Finally, $\mathrm{Z}$ tests revealed that the sample respondents' age and weekly household income are not significantly different than the median age and weekly average income of the Sydney and the national populations.

Table 1 Summary statistics of respondents' socio-economic characteristics

\begin{tabular}{|c|c|c|c|c|}
\hline \multicolumn{2}{|l|}{ Respondent characteristic } & \multirow{2}{*}{$\begin{array}{l}\text { Sample } \\
0.90\end{array}$} & \multirow{2}{*}{$\begin{array}{l}\text { Sydney } \\
\text { average } \\
1.16\end{array}$} & \multirow{2}{*}{$\begin{array}{l}\text { National } \\
\text { average }\end{array}$} \\
\hline Sex ratio (male/female) & & & & \\
\hline \multirow[t]{3}{*}{ Respondent age distribution (\%) } & 18 to 34 years & 46 & $36^{\mathrm{a}}$ & $35^{\mathrm{a}}$ \\
\hline & 35 to 54 years & 42 & $35^{\mathrm{a}}$ & $35^{\mathrm{a}}$ \\
\hline & 55 and above & 12 & $29^{a}$ & $30^{\mathrm{a}}$ \\
\hline \multirow[t]{3}{*}{ Highest level of education (\%) } & Year 12 or below & 32 & 36 & 51 \\
\hline & Certificate & 30 & 21 & 16 \\
\hline & $\begin{array}{l}\text { Bachelor's degree } \\
\text { or above }\end{array}$ & 38 & 44 & 22 \\
\hline $\begin{array}{l}\text { Gross average household } \\
\text { income (AUD/week) }\end{array}$ & & 1450 & 1360 & 1305 \\
\hline \multirow{4}{*}{$\begin{array}{l}\text { Income distribution }{ }^{\mathrm{b}} \\
\text { ( } \% \text { of household })\end{array}$} & Below AUD 600/week & 14 & & 23 \\
\hline & Below AUD 1300/week & 27 & & 28 \\
\hline & Below AUD 2000/week & 33 & & 21 \\
\hline & Above AUD 2000/week & 26 & & 29 \\
\hline
\end{tabular}

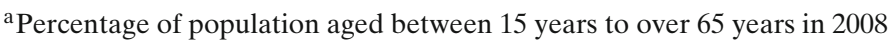

${ }^{\mathrm{b}}$ Break-down of gross weekly income was not available for Sydney population

Australian Bureau of Statistics (2009) 
A more detailed break-down of the sample with respect to age reveals that relatively younger people (aged between 18 and 54 years) are over represented. The difference between sample age distribution with Sydney and National population were found to be significant at the $1 \%$ level. This is perhaps an impact of using the internet as a survey mode. Younger people are more likely to use the internet than older people. Further, some discrepancy was observed between national and sample population characteristics with respect to the distribution of income. It appears that relatively low and high income households are under represented in the sample. The difference in income distribution between sample and national population was significant at the $5 \%$ level.

\section{Perceptions of climate change}

\subsection{Concerns and beliefs of anthropogenic climate change}

Respondents were asked to rank five policy issues (climate change, education, health care, law and order and the economy) in Australia according to their levels of relative importance. Twelve percent of the respondents ranked climate change as the most important policy issue. About a third of the respondents indicated the economy is the most important policy issue while a further third felt that health care facility should be the top priority. Less than a quarter $(20 \%)$ of the respondents indicated that they were 'highly concerned' about the impact of climate change in Australia. The majority (40\%) were 'concerned'. About a third of the respondents were 'somewhat concerned' while around $10 \%$ were 'not so concerned' or 'not at all concerned'. A quarter $(25 \%)$ of the respondents expressed strong agreement with the statement that climate change is caused by human activity. Almost half of the sample respondents (48\%) indicated a moderate level of agreement. Eighteen percent of the respondents neither agreed nor disagreed and the rest opposed the statement. Respondents' level of agreement to this statement and their levels of concern about climate change are found to be significantly positively correlated $(\mathrm{r}=$ $0.425, p<0.001)$. This implies that, on average, respondents who stated higher levels of concern about climate change, also believed that human actions were responsible for the changing climatic conditions.

\subsection{Perceptions of the scale of unmitigated climate change and effectiveness of mitigation action}

Respondents' mean best guess about change in average temperature in 2100 relative to the current year was $3.75^{\circ} \mathrm{C}$. The median was $3^{\circ} \mathrm{C}$ with a maximum of $10.5^{\circ}$ and minimum of $-4.5^{\circ} \mathrm{C}$. In comparison to the official best estimate temperature change projections $\left(5.1^{\circ} \mathrm{C}\right)$ in 2100 (CSIRO 2008), sample respondents' perceptions of the scale of climate change appear to be low. About two thirds of the respondents' best guess temperature change was below $5^{\circ} \mathrm{C}$ while a minority of less than $5 \%$ believed average yearly temperature would decline in 100 years time. Ninety percent of those who believed temperature change would exceed $5^{\circ} \mathrm{C}$ were believers in human induced climate change whereas about two thirds of those who stated negative temperature change did not agree with the statement that climate change is caused 
by human action. The average range (average difference between high guess and low guess) was about $3^{\circ} \mathrm{C}$. The range of predicted temperature change varied within $15.5^{\circ}$ and $0^{\circ} \mathrm{C}$.

The mean of respondents' best guess of the CPRS being effective in slowing down climate change without global co-operation was $25 \%$. The interpretation of this value according to the IPCC likelihood scale is 'Unlikely'. The average range around this best guess was also 25\%. This implies that respondents' beliefs of the success of the CPRS without a global co-operation varied between 'Less Likely than Not' and 'Highly Unlikely'. When respondents were asked to indicate their perceptions of best guess of the likelihood of the CPRS being effective with global co-operation, over two thirds $(71 \%)$ of the respondents selected a higher probability along the scale, $12 \%$ respondents did not update their perceptions while $16 \%$, surprisingly, stated a lower probability. ${ }^{3}$ The average best guess likelihood, in the second scenario, was $45 \%$. According to the IPCC scale, this implies 'Less Likely than Not'. The average range around this best guess was slightly lower (21\%) than the first scenario (without global co-operation). This value implies that respondents' beliefs of the success of the CPRS with a global co-operation varies between 'More Likely than Not' and 'Unlikely'. The mean difference between respondents' best guesses of likelihood of the effectiveness of the CPRS with and without a global co-operation is statistically significant at the $1 \%$ level $(Z=19, p<0.001)$. The stated average range around the best guess of the effectiveness of the CPRS with global co-operation is also significantly $(\mathrm{Z}=4.2, p<0.001)$ lower than the stated range without global co-operation.

Respondents were asked to convey their perceptions of likelihood of the world reaching an agreement on climate change mitigation on a scale of $0 \%$ and $100 \%$. More than $80 \%$ of the respondents believed that the chance was below $50 \%$ while half of them believed that the chance is less than $30 \%$, i.e. unlikely. A high and significant positive correlation $(\mathrm{r}=0.50, p<0.001)$ was observed between respondents' best guess of policy effectiveness with global co-operation and their best guess of likelihood of achieving a global co-operation. This implies that, on average, respondents who stated higher best guess of policy effectiveness with global co-operation were also more optimistic about a multilateral agreement on climate change mitigation.

\subsection{Perceptions of the impacts of unmitigated climate change}

Figure 1 presents respondents' expectations of the effect of unmitigated climate change. Decreases in water supply and in agricultural production and increases in drought events and damage to the Great Barrier Reef were cited by a majority of the respondents as impacts that Australia may experience. Loss of biodiversity, damage to Kakadu wetlands and increased health problems were also mentioned by respondents as expected consequences of climate change. Respondents were asked to indicate how they expected their households would be affected by climate

\footnotetext{
${ }^{3}$ It is unclear why a group of respondents believed a global co-operation would reduce the likelihood of the Australian policy to be effective. One plausible explanation could be that these respondents could not recall the likelihood they selected in the previous question. The survey interface was programmed in a way that did not allow them to go backward to change or review their answers.
} 


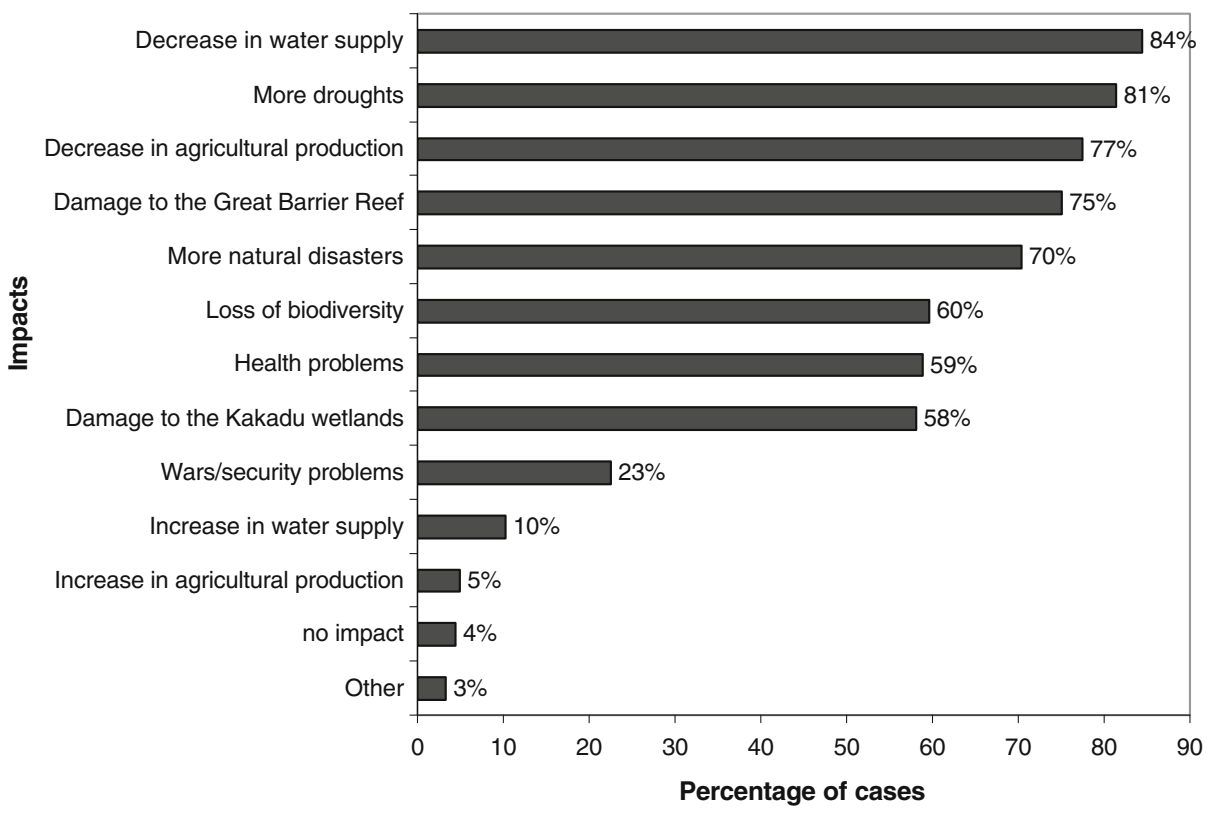

Fig. 1 Respondents' perceptions of climate change impact on Australia

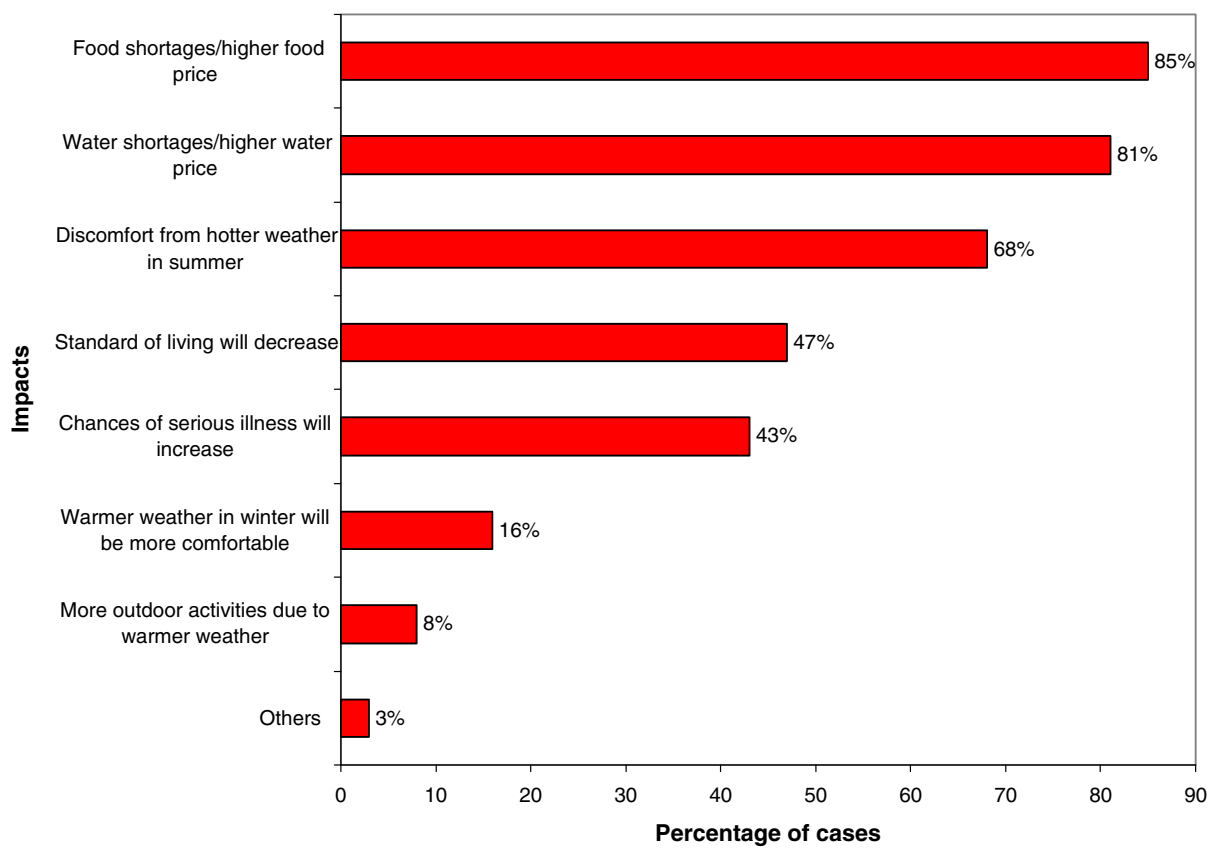

Fig. 2 Respondents' perceptions of climate change impact on their households 
change if no climate change mitigation action was undertaken. The responses to this question are summarized in Fig. 2. Higher prices for food and water resulting from lower food and water supplies were the major concerns reported at the household level. Discomfort due to hotter weather and decreases in the standard of living were also mentioned. About $7 \%$ of the total respondents, nevertheless, referred to some positive impacts of climate change such as increased amount of outdoor activities and relatively warmer weather during winter time.

\section{Household preferences for climate change mitigation}

\subsection{Determinants of actual behaviour}

Over one third $(41 \%)$ of the sample respondents indicated that they reduced their use of motorized vehicles while over two thirds (67\%) stated that they reduced their use of electricity to reduce their carbon footprint. In total, over $70 \%$ of the sample respondents $(n=456)$ reduced either their use of electricity or motorized vehicle or both. A multivariate probit regression model is estimated to identify the determining factors of individual decisions to reduce their carbon consumption. The results are presented in Table 2. The coefficients of the variables TV/News (respondents who watched television program on climate change and/or read newspaper article) and Inconvenient Truth (respondents who watched An Inconvenient Truth) are positive and significant at the 1 and $10 \%$ level. These results imply that mass media exposure significantly influences people's desires to take action against climate change. These findings are consistent with findings of the public perception literature which suggest that lay people gain most of their knowledge about science from the mass media (Wilson 1995). Lowe et al. (2006) found that the film The Day after Tomorrow ${ }^{4}$ raised viewers' awareness of climate change and enhanced their motivations to act on climate change mitigation. Nolan (2010) showed that watching An Inconvenient Truth increased viewers' concern for the environment and their willingness to reduce GHGs emissions.

In addition to the mass media exposure, perceptions of temperature change and socio-demographic characteristics were found to be influencing respondents' GHG reduction behaviours. The coefficient of the variable Temperature (respondents' best guesses of temperature change) is positive and significant at the $5 \%$ level. This implies that respondents, who stated higher best guesses of temperature change, were more likely to act against climate change at the individual level. The coefficients of the variables Female and Income are positive and statistically significant at the 10 and $5 \%$ level respectively. These results imply that female respondents are more likely to reduce their carbon consumption than their male counterparts and that the desire for climate change mitigation increases with increased household income. The coefficient of Education (respondents who had university degree) is significant and negative. This implies that university graduates are less likely to reduce their carbon emissions at the individual level. This result might appear to be counterintuitive as

\footnotetext{
${ }^{4}$ The Day After Tomorrow is a science-fiction film released in 2004. The film portrays the catastrophic impacts of abrupt climate change effects by depicting a series of different extreme weather events across the world.
} 
Table 2 Probit regression model of actual behaviour to reduce carbon footprint (dependent variable: respondents reduced their car and/or electricity use $=1$, otherwise $=0$ )

\begin{tabular}{|c|c|c|}
\hline Variable name & Variable description & Coefficient (SE) \\
\hline Constant & & $-0.38 *(0.20)$ \\
\hline \multicolumn{3}{|c|}{ Exposure to the mass media } \\
\hline $\begin{array}{l}\text { Inconvenient } \\
\text { Truth }\end{array}$ & $\begin{array}{l}\text { Respondents watched 'An Inconvenient Truth' } \\
\quad(\text { Yes }=1 \text {, otherwise }=0)(\text { mean }=0.27, \mathrm{SD}=0.45)\end{array}$ & $0.28 * *(0.13)$ \\
\hline TV/NEWS & $\begin{array}{l}\text { Respondents watched television program and/or } \\
\text { read newspaper article on climate change } \\
(\mathrm{Yes}=1 \text {, otherwise }=0)(\text { mean }=0.87, \mathrm{SD}=0.33)\end{array}$ & $0.56 * * *(0.16)$ \\
\hline \multicolumn{3}{|c|}{ Perceptions of the scale of climate change } \\
\hline Temperature & $\begin{array}{l}\text { Best guess of temperature change in } 100 \text { years } \\
\quad(\text { mean }=3.7, \mathrm{SD}=2.9)\end{array}$ & $0.04 * *(0.02)$ \\
\hline \multicolumn{3}{|c|}{ Socio-demographic characteristics } \\
\hline Education & $\begin{array}{l}\text { Respondent have university degree } \\
\quad(\text { Yes }=1, \text { otherwise }=0)(\text { mean }=0.38, \mathrm{SD}=0.47)\end{array}$ & $-0.23 * *(0.11)$ \\
\hline Female & $\begin{array}{l}\text { Respondent is female }(\text { Yes }=1 \text {, otherwise }=0) \\
\quad(\text { mean }=0.53, \mathrm{SD}=0.5)\end{array}$ & $0.33 * * *(0.11)$ \\
\hline Income & $\begin{array}{l}\text { Monthly household income per person } \\
\text { in thousand AUD }(\text { mean }=2.2,0.38, \mathrm{SD}=1.5)\end{array}$ & $0.09 * *(0.04)$ \\
\hline \multicolumn{3}{|c|}{ Model fit statistics } \\
\hline Log-likelihood & & -355 \\
\hline Wald $\chi^{2}$ & & $41(d f=6, p<0.001)$ \\
\hline$N$ & & 634 \\
\hline
\end{tabular}

$* * * p<0.01 ; * * p<0.05 ; * p<0.10$

one would expect more highly educated people to care more about the environment. However, it might be that university graduates believed reduction in GHG emissions at the individual level is insignificant in the global context.

\subsection{Determinants of support for the CPRS}

\subsubsection{Responses to the WTP questions}

Figure 3 summarizes responses to the first and the second WTP questions. Sixtyseven percent of the 634 respondents interviewed rejected the offered bid. Respondents who rejected the bid amount were asked in a follow-up question to indicate their reasons for not paying. Some of the reasons mentioned by the respondents are common to most $\mathrm{CV}$ studies concerning to the provision of public good: financial constraints $(18 \%)$ and holding other parties (Government, polluters) responsible for paying $(33 \%)$. Some respondents refused to support the CPRS because of reasons that could be broadly translated into the imprecision of climate science. Five percent of those who refused to pay expressed their disbelief about the effectiveness of the CPRS in slowing down climate change while $8 \%$ indicated the lack of scientific evidence about climate change as the reason for not wanting to pay. Eleven percent stated that they did not want to pay because they were not told what to expect in terms of climate change benefit if they did pay. About $8 \%$ of the respondents indicated that they would pay on the condition that major GHG emitting countries had implemented a similar scheme. 
$1^{\text {st }}$ WTP question:

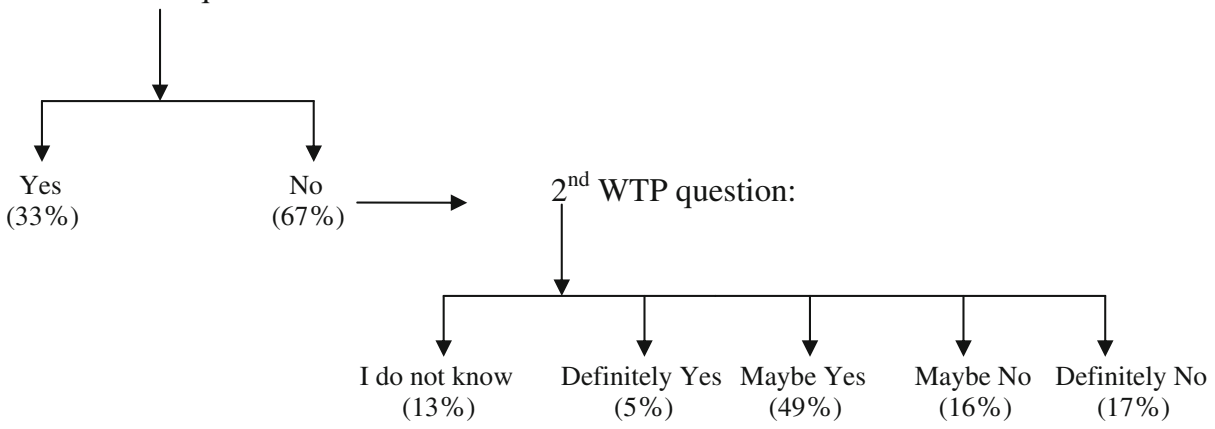

Fig. 3 Responses to the WTP questions

Respondents who said 'No' to the first WTP question were asked whether they would be willing to pay if a global co-operation could be reached. A polychotomous choice format (I don't know, Definitely Yes, Maybe Yes, Definitely No, Maybe No) was applied to allow respondents to express their levels of confidence with their decision (Ready et al. 1995). Five percent $(n=21)$ of those who said 'No' to the first WTP question indicated that they would definitely pay if the major GHG emitting countries implement a similar scheme. About 50\% $(n=208)$ selected the 'Maybe Yes' option as a response to this question. Thirteen percent of the respondents said that they were unsure about their preferences and the rest said that they would not pay.

Respondents' perceptions of likelihood of a global co-operation were examined across their responses to the first and second WTP questions. Respondents who said 'Yes' to the first WTP questions, on an average, stated significantly higher likelihood $(\mathrm{Z}=2.6, p<0.001)$ of a multilateral agreement on GHG emissions reduction than those who said 'No'. Respondents who said 'Definitely Yes' and 'Maybe Yes' to the second WTP question were, on average, significantly less optimistic $(\mathrm{Z}=2.7, p<$ 0.001 ) of a multilateral agreement than other respondents who said 'No' to the first WTP question.

The probability distribution function (PDF) of the stated WTP (responses to the first WTP question) for the CPRS based on a total of 634 valid observations for the WTP question is presented in Fig. 4. The PDF function falls sharply starting from bid level AUD 20 up to bid level AUD 300. At the bid level AUD 400, the proportion of 'Yes' responses rises. The proportion of respondents saying 'Yes' to AUD 400 was significantly (chi square $=3.8, p<0.05$ ) higher than the proportion of respondents saying 'Yes' to AUD 300. The differences in socio-economic and attitudinal characteristics of two groups of respondents-those who were presented with the AUD 400 amount and all others-were examined. No statistically significant differences were observed in terms of their age, education, income or occupation. No statistically significant difference existed with respect to respondents' familiarity, attitude towards climate change or their level of concerns for climate change.

\subsubsection{Multivariate regression results}

The binary probit regression approach was applied to estimate the effects of the explanatory variables on the binary discrete choice of paying for the CPRS. Table 3 
Fig. 4 Probability distribution function of the stated WTP

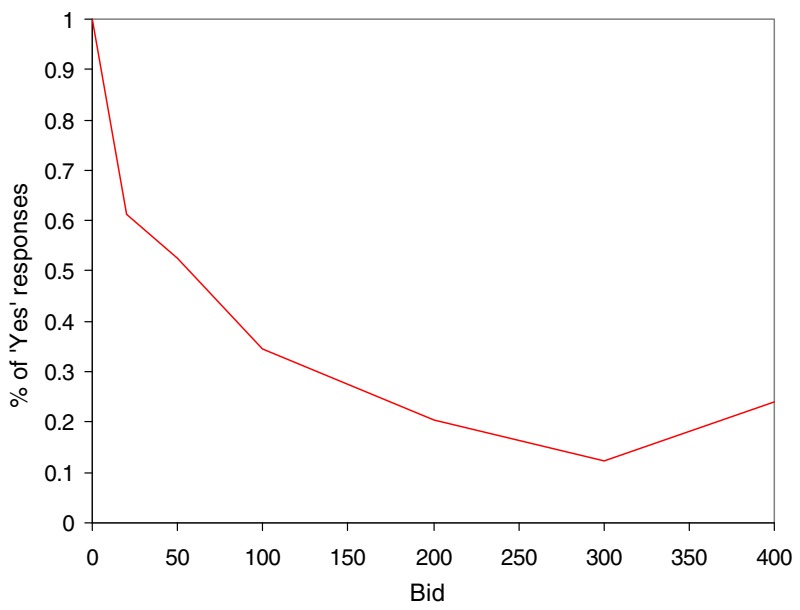

presents the regression results. In addition to the variables listed in Table 3, numerous other variables including the stated range of temperature change, best guess of likelihood of a global agreement, exposure to TV and newspaper and a range of demographic factors, e.g. sex and age, were included in the regression model. ${ }^{5}$ No statistically significant impact was found of any of these variables on the probability of saying 'Yes' or 'No' to the WTP questions.

In Table 3, the multivariate regression results for two different models are set out. The models vary based on the different WTP responses used as the dependent variable. The 'Yes/No' responses ${ }^{6}$ to the first WTP question were used as the dependent variable in Model 1. To create the dependent variables for analysis of WTP when global co-operation was assured, the 'No' responses obtained from the first WTP question were calibrated (recoded to 'Yes') based on the responses to the second WTP question. If respondents replied 'Definitely Yes' to the second WTP question then the corresponding 'No' responses to the first WTP question were recoded to 'Yes'. These recoded responses were used as the dependent variable in Model 2. Although both of the estimated regression models presented in Table 3 are statistically significant at the $1 \%$ level, Model 1 is the best fitting in terms of the Pseudo $R$ Squared. In both models, the coefficients of the variable BID, the extra monthly expenses households were asked to pay for the CPRS, are statistically significant and show the a priori expected negative sign (i.e. the higher the bid, the lower the probability that respondents were willing to pay).

The coefficients of the variables Temperature (respondents' best guess of temperature change in 100 years time) and Temperature Squared are statistically significant in Model 1 and 2. The signs of the coefficients of Temperature (positive) and Temperature Squared (negative) demonstrate that the utility function is concave in climate change scale expectations. As expected future temperatures increase, the

\footnotetext{
${ }^{5}$ The utility function is assumed to be linear in income. Therefore, 'Income' drops out from the utility difference function which is essentially the WTP function estimated in Table 3.

${ }^{6}$ Note that no recoding was undertaken to the original 'Yes/No' responses.
} 
Table 3 Probit regression models of stated preference ('Yes/No' replies to WTP question is response variable; Yes $=1$, otherwise $=0$ )

\begin{tabular}{|c|c|c|c|}
\hline Variable name & Variable description & Model $1^{\mathrm{a}}$ & Model $2^{\mathrm{b}}$ \\
\hline Constant & & $0.006(0.27)$ & $0.15(0.26)$ \\
\hline BID & $\begin{array}{l}\text { Increased household expenses } \\
\quad(\text { per household/month) } \\
(\text { mean }=86, \mathrm{SD}=122)\end{array}$ & $-0.003 * * *(0.0005)$ & $-0.003 * * *(0.0005)$ \\
\hline \multicolumn{4}{|c|}{ Scenario and policy uncertainty } \\
\hline Temperature & $\begin{array}{l}\text { Best guess of temperature } \\
\text { change in } 100 \text { years time } \\
(\text { mean }=3.7, \mathrm{SD}=2.9)\end{array}$ & $0.15 * *(0.07)$ & $0.12 *(0.07)$ \\
\hline Temperature Squared & $\begin{array}{l}\text { Square of Temperature } \\
\quad(\text { mean }=22, S D=30)\end{array}$ & $-0.016 * *(0.007)$ & $-0.012 *(0.006)$ \\
\hline Policy & $\begin{array}{l}\text { Best guess probability } \\
\text { of the CPRS not being } \\
\text { effective in slowing down } \\
\text { climate change } \\
(\text { mean }=55, \mathrm{SD}=27)\end{array}$ & $-0.02 * *(0.017)$ & $-0.01 * * *(0.002)$ \\
\hline \multicolumn{4}{|l|}{ Media, familiarity } \\
\hline Inconvenient Truth & $\begin{array}{l}\text { Respondents' } \\
\text { watched the documentary } \\
\text { An Inconvenient Truth } \\
(\text { Yes }=1, \text { otherwise }=0) \\
(\text { mean }=0.27, \mathrm{SD}=0.455)\end{array}$ & $0.47 * * *(0.13)$ & $0.41 * * *(0.12)$ \\
\hline CPRS & $\begin{array}{l}\text { Respondents have } \\
\text { heard about the CPRS } \\
(\text { Yes }=1, \text { otherwise }=0) \\
(\text { mean }=0.55, \mathrm{SD}=0.5)\end{array}$ & $0.25 * *(0.12)$ & $0.22 *(0.11)$ \\
\hline \multicolumn{4}{|l|}{ Actual behaviour } \\
\hline Offsets & $\begin{array}{l}\text { Respondents have } \\
\text { purchased carbon offsets } \\
(\text { Yes }=1, \text { otherwise }=0) \\
(\text { mean }=0.11, \mathrm{SD}=0.31)\end{array}$ & $0.31 *(0.17)$ & $0.19(0.17)$ \\
\hline Solar Power & $\begin{array}{l}\text { Household uses solar energy } \\
\quad(\text { Yes }=1, \text { otherwise }=0) \\
(\text { mean }=0.06, \mathrm{SD}=0.24)\end{array}$ & $0.39 *(0.24)$ & $0.56 * *(0.23)$ \\
\hline \multicolumn{4}{|c|}{ Impacts of Climate Change } \\
\hline Biodiversity & $\begin{array}{l}\text { Climate change } \\
\text { will cause biodiversity } \\
\text { loss in Australia } \\
(\text { Yes }=1, \text { otherwise }=0) \\
(\text { mean }=0.58, \mathrm{SD}=0.49)\end{array}$ & $0.28 * *(0.13)$ & $0.28 *(0.12)$ \\
\hline Food Price & $\begin{array}{l}\text { Climate change will } \\
\text { increase food prices } \\
(\text { Yes }=1, \text { otherwise }=0) \\
(\text { mean }=0.81, \mathrm{SD}=0.39)\end{array}$ & $-0.35^{* *}(0.16)$ & $-0.25^{*}(0.15)$ \\
\hline Discomfort & $\begin{array}{l}\text { Hotter summer will } \\
\text { cause discomfort } \\
\quad(\text { Yes }=1, \text { otherwise }=0) \\
(\text { mean }=0.64, \text { SD }=0.47)\end{array}$ & $0.24 *(0.13)$ & $0.12(0.13)$ \\
\hline
\end{tabular}


Table 3 (continued)

\begin{tabular}{|c|c|c|c|}
\hline Variable name & Variable description & Model $1^{\mathrm{a}}$ & Model $2^{\mathrm{b}}$ \\
\hline Comfort & $\begin{array}{l}\text { Hotter weather will be } \\
\text { comfortable in winter } \\
(\text { Yes }=1, \mathrm{No}=0) \\
(\text { mean }=0.15, \mathrm{SD}=0.36)\end{array}$ & $-0.38 * *(0.18)$ & $-0.20(0.016)$ \\
\hline \multicolumn{4}{|c|}{ Demographic characteristics } \\
\hline Education & $\begin{array}{l}\text { Respondents have } \\
\text { a university degree } \\
\quad(\text { Yes }=1, \text { otherwise }=0) \\
(\text { mean }=0.38, \mathrm{SD}=0.47)\end{array}$ & $0.24 * *(0.12)$ & $0.24 * *(0.11)$ \\
\hline \multicolumn{4}{|c|}{ Model fit statistics } \\
\hline Log-likelihooc & & -325 & -349 \\
\hline Wald $\chi^{2}$ & & $146(d f=13, p<0.001)$ & $126(d f=13, p<0.001)$ \\
\hline Pseudo $R \mathrm{Squ}$ & & 0.18 & 0.15 \\
\hline$N$ & & 634 & 634 \\
\hline
\end{tabular}

${ }^{a}$ Responses to the first WTP question as dependent variable

' 'No' response to the first WTP question was recoded to 'Yes' if response to the second WTP question was 'Definitely Yes'

Standard errors of the parameter estimates between brackets

*** $p<0.01 ; * * p<0.05 ; * p 0.10$

likelihood of paying for the CPRS increases. However, the likelihood increases at a decreasing rate. The coefficients of the variable Policy (respondents' best guess of likelihood that the CPRS will not be effective in slowing down climate change with global co-operation) are statically significant in both Models 1 and 2. This implies that, on average and other things remaining the same, the higher the subjective likelihood of the CPRS being ineffective in mitigating climate change (with global co-operation) the lower was the support for the CPRS.

The coefficient of the variable Inconvenient Truth (respondents watched An Inconvenient Truth) is statistically significant and positive at the $1 \%$ level. This finding reinforces the significance of the media in influencing lay people's preferences for climate change mitigation. The variable CPRS (respondents' have heard about the CPRS before the survey) was used as an indicator of respondents' familiarity to the policy context. The coefficients of CPRS are statistically significant at the $10 \%$ level in Models 1 and 2. This implies that respondents who heard about the CPRS prior to the survey were significantly more likely to accept the offered bid level.

Respondents' actual behaviours towards climate change mitigation and their stated support for the CPRS were found to be consistent. The coefficient of Offsets carbon is statistically significant and positive in Model 1, implying that respondents who have purchased carbon offsets are significantly more likely to pay for the CPRS even when global co-operation is not guaranteed. The influence of this variable in determining respondents' support for the CPRS becomes insignificant with a guaranteed global co-operation (Model 2). The variable Solar Power refers to those respondents who installed solar energy in their houses to reduce their consumption of carbon intensive electricity. The coefficient of Solar Power is significant at the $10 \%$ level in Model 1 and at 5\% level in Model 2. The positive signs of the coefficients denote that respondents who were willing to reduce carbon emissions at the household level were also supportive of the national emissions reduction scheme. 
Respondents' perceptions of the impacts of climate change on Australia and on their households have statistically significant influence on their decisions to support the CPRS. First, respondents who believed unmitigated climate change would negatively impact Australia's biodiversity, on an average, were significantly more likely to accept the offered bid level. Second, respondents who believed climate change would have some positive impacts such as comfortable winter weather, were significantly less likely to accept the offered bid level. Conversely, those respondents who believed higher temperature would cause discomfort during summer were significantly more likely to support the proposed mitigation action. However, the coefficients of Comfort and Discomfort are not statistically significant at the $10 \%$ level in Model 2.

The coefficients of the variable Food Price (climate change would cause higher food prices) are statistically significant at the $10 \%$ level in Models 1 and 2 . The negative signs of the estimated coefficients imply that respondents who believed climate change would cause higher food prices were significantly less likely to accept the offered bid level. This result may be plausible because of the nature of the payment vehicle used in the study which is, increased prices of necessary goods and services. Respondents might have thought that the likely increase in food price due to unmitigated climate change would be lower than the offered bid level, i.e. the increased household expenditure triggered by the proposed mitigation measure.

The coefficient of Education (respondents who had a university degree) is positive and statistically significant at the 5\% level. This implies that respondents who had a university degree were more likely to support the mitigation policy at the national level.

\subsubsection{Estimation of mean WTP}

A range of different mean WTP estimates obtained under different distributional assumptions are presented in Table 4. The CVM programs in STATA were used to estimate the Krinsky and Robb (1986) confidence intervals for the point estimates of mean WTP by applying 5000 replications. The lowest value of mean WTP, AUD 16 per household per month, is obtained from Model 1 (without guaranteed global co-operation) $\left(\mathrm{WTP}_{1}\right)$. The $95 \%$ confidence interval of $\mathrm{WTP}_{1}$ ranges from AUD-54 to 60. This implies that $\mathrm{WTP}_{1}$ is not statistically different from zero. The mean WTP from Model 2 (with guaranteed global co-operation) $\left(\mathrm{WTP}_{2}\right)$ is AUD 38. This later estimate is also not significantly different than zero as its $95 \%$ confidence interval ranges between AUD-34 and 80 .

Both $\mathrm{WTP}_{1}$ and $\mathrm{WTP}_{2}$ were obtained by exploiting the full distribution of the WTP responses. The estimates are associated with a large confidence interval (6

Table 4 Krinsky and Robb confidence intervals of Mean WTP for the CPRS using 5000 repetitions

\begin{tabular}{llll}
\hline & \multicolumn{2}{l}{ Mean WTP (Per household/per month in AUS\$) (95 \% C.I) } \\
\cline { 2 - 4 } & $\begin{array}{l}\text { (without guaranteed } \\
\text { global co-operation) }\end{array}$ & $\begin{array}{l}\text { (with guaranteed global } \\
\text { co-operation) }\end{array}$ & $\begin{array}{l}\text { Difference significant } \\
\text { (probability) }\end{array}$ \\
\hline Untruncated model $^{\mathrm{a}}$ & $16(-54$ to 60$)$ & $38(-34$ to 80$)$ & 0.01 \\
Truncated model $^{\mathrm{b}}$ & $54(19$ to 78$)$ & $69(33$ to 93$)$ & 0.02 \\
\hline
\end{tabular}

${ }^{a}$ This model includes all observations $(n=634)$

${ }^{\mathrm{b}}$ This model excludes 83 responses to bid level $400(n=551)$ 
and 3 times the mean values of $\mathrm{WTP}_{1}$ and $\mathrm{WTP}_{2}$ respectively), as a result, the $95 \%$ confidence interval includes negative values. These results could be caused by the fat-tail PDF presented in Fig. 4. To overcome this problem, mean WTP values were estimated from a truncated PDF distribution. This involved exclusion of 83 respondents who were offered the bid level AUD 400 from the dataset. The binary probit regression models presented in Table 3 were re-estimated using the remaining observations $(n=551)$. The estimated mean WTP from a truncated distribution with and without a guaranteed global co-operation are AUD $54\left(\mathrm{WTP}_{1 \mathrm{~T}}\right)$ and AUD 69 $\left(\mathrm{WTP}_{2 \mathrm{~T}}\right)$ per household per month respectively. These values are higher than the mean WTP values estimated from the untruncated distribution. Further, the $95 \%$ confidence intervals of $\mathrm{WTP}_{1 \mathrm{~T}}$ and $\mathrm{WTP}_{2 \mathrm{~T}}$ do not include negative values. This implies that $\mathrm{WTP}_{1 \mathrm{~T}}$ and $\mathrm{WTP}_{2 \mathrm{~T}}$ are significantly different than zero at the $5 \%$ level.

$\mathrm{WTP}_{1}\left(\mathrm{WTP}_{1 \mathrm{~T}}\right)$ and $\mathrm{WTP}_{2}\left(\mathrm{WTP}_{2 \mathrm{~T}}\right)$ were tested for their differences. ${ }^{7}$ The difference between $\mathrm{WTP}_{1}$ and $\mathrm{WTP}_{2}$ was found to be statistically significant at the $1 \%$ level while the difference between $\mathrm{WTP}_{1 \mathrm{~T}}$ and $\mathrm{WTP}_{2 \mathrm{~T}}$ was significant at the $5 \%$ level. This result needs cautious interpretation. It is important to note that $\mathrm{WTP}_{1}$ $\left(\mathrm{WTP}_{1 \mathrm{~T}}\right)$ does not reflect individual WTP for climate change mitigation without a global co-operation. When respondents were asked the first WTP question, they were told to keep their perceptions of likelihood of achieving a global co-operation in mind while answering this question. The objective of the second WTP question was modest. This question was asked to detect those respondents who rejected the offered bid level solely due to their lack of confidence in achieving a broader global co-operation. Therefore, this result implies that a significant proportion of respondents refused to pay because of their low perceptions of likelihood of a global co-operation. If this particular group of respondents could be assured about achieving a broader global consensus, the mean WTP estimate for climate change mitigation would be significantly higher.

\section{Discussions and conclusions}

The study aims to provide an understanding of Australian households' perceptions of climate change and their preferences for the proposed CPRS. A sample of over 600 Sydney residents, about two thirds of whom were concerned about climate change and almost three quarters of whom believed climate change is caused by human action, attached relatively low levels of importance to climate change in comparison to other competing policy issues in Australia. Consistent with their priorities, a majority of $67 \%$ of the respondents rejected the prospect of paying extra household expenses to support the proposed emissions reduction scheme. Household support for the scheme varied negatively with its potential cost. At a relatively lower level of cost, more households were supportive of the policy. The support for the policy declined as cost increased.

\footnotetext{
${ }^{7}$ Note that the conventional Poe test (Poe et al. 1994) is not appropriate to test the difference between mean WTP estimates obtained from the same sample as they are not independently distributed. A non-parametric test has been applied here. The details of this test procedure can be obtained from the authors.
} 
A majority of the respondents was found to be ignorant of the official projection of the scale of climate change in Australia. Two thirds of respondents believed that the temperature rise would be lower than what has been officially projected. A significant non-linear relationship was observed between the likelihood of accepting an offered bid level and respondents' stated best guess temperatures. ${ }^{8}$ Respondents were willing to trade off more money as the expectations of temperature increases rose. The likelihood of accepting the offered bid increased at a decreasing rate. Although this result is consistent with the finding of Cameron (2005), the implication of the finding may reflect public misunderstanding or mistrust of climate science. The IPCC fourth assessment report indicates that predicted climate change impacts are characterized by thresholds effect (IPCC 2007). This means that increases in temperature beyond a threshold may result in dramatic change. Consequently, the damages caused by climate change, measured in economic terms, are likely to increase at an increasing rate with increase in temperatures.

The results of our survey reveal that the general public lacks confidence in the effectiveness of climate change mitigation measure. Sample respondents stated significantly lower chances of the mitigation measure being successful when the USA, India and China are not committed to the mitigation effort. Under the assumption that a global co-operation is achieved, respondents' best guess of likelihood of the CPRS being successful did not exceed $50 \%$. This lack of confidence could be an outcome of the complexity embedded in climate change science as well as the complexity surrounding the global political architecture of climate change mitigation. However, respondents' mean likelihood of success of the CPRS was significantly higher in the 'with co-operation scenario' than the 'without co-operation scenario'. This implies that the general public believes that global co-operation significantly enhances the chance of mitigation measures being effective. As expected, respondents' lack of confidence in climate change policy effectiveness influenced their decisions to support the CPRS. A significant linear, negative relationship was observed between respondents' 'Yes/No' responses to the WTP question and their degree of disbeliefs in the policy effectiveness.

Respondents' willingness to take action against climate change-both at the individual and national level — are determined by their exposures to the mass media. People who watched 'An Inconvenient Truth' were significantly more likely to support the proposed CPRS. The influence of mass media was equally significant when people's actual behaviour to combat climate change was analyzed. Respondents who watched 'An Inconvenient Truth' or who watched television program or newspaper article on climate change, were significantly more likely to adapt to behaviours that lead to lower carbon pollution. Education was found playing an interesting role in determining public support for climate change abatement at the individual and national level. Respondents, who had a university degree, on average, were more likely to support GHG emissions reduction at the national level but less likely to change their consumption of carbon intensive goods at the individual level. These findings are intuitively consistent. A university graduate is more likely to be aware that individual emissions are too insignificant to have any significant impact on climate change mitigation.

\footnotetext{
${ }^{8}$ Unlike Cameron (2005), we did not find any statistically significant relationship between public support of climate change policy and the range of respondents' perceived temperature change.
} 
On average, sampled households were willing to bear between AUD 17 and 68 extra household expenditure per month. This amount is about quarter of a percent to $1 \%$ of average monthly household income of the sample population and less than $50 \%$ of the projected increase in household expenditure due to the introduction of the CPRS (The Commonwealth Treasury 2008). Caution need to be applied while assessing these values. Given that our sample was drawn from the Sydney population, the mean WTP should not be interpreted as Australian households' WTP. Further, the survey was conducted using an internet panel. This survey mode precludes those households who do not have an internet connection or who do not use a computer. In addition, the inherent self-selection bias associated with an internet survey needs to be taken into account while aggregating these values over national population. Finally, biases (e.g. payment vehicle, framing and information bias) associated with the $\mathrm{CV}$ method need to be taken into careful consideration when using these values for public policy analysis.

Finally, a significant difference was observed in respondents' support of the climate policy based on their perceptions of the likelihood of global policy cooperation. Respondents, who believed that global co-operation was more likely, were significantly more supportive of the CPRS. Further, mean WTP was adjusted by taking into account the preferences of those respondents who refused to pay solely because of the absence of a multilateral agreement on climate change mitigation. The difference between mean WTP with and without guaranteed global co-operation was statistically significant at the $1 \%$ level. This implies that if a broader global consensus on GHG reduction effort could be assured, willingness to pay for climate change policy intervention would increase substantially. This may not be entirely because respondents believe a global co-operation is the key to climate change mitigation. The increased support for a national mitigation measure when the rest of the world co-operates, perhaps, arises from the philosophy of all countries doing their fair share.

Acknowledgements The work presented in this paper is funded by the Environmental Economics Research Hub. We gratefully acknowledge Dr. Frank Jotzo and Dr Stephen Howes for their comments on the questionnaire.

Open Access This article is distributed under the terms of the Creative Commons Attribution Noncommercial License which permits any noncommercial use, distribution, and reproduction in any medium, provided the original author(s) and source are credited.

\section{References}

Australian Bureau of Statistics (2009) 2008 year book of Australia. Australian Bureau of Statistics, Canberra

Berk RA, Fovell RG (1999) Public perceptions of climate change: a willingness to pay assessment. Climatic Change 41:413-446

Berrens RP, Bohara AK, Jenkins-Smith HC, Silva CL, Weimer DL (2004) Information and effort in contingent valuation surveys: application to global climate change using national internet samples. J Environ Econ Manag 47:331-363

Cameron TA (2005) Individual option prices for climate change mitigation. J Public Econ 89:283-301

Carson R, Groves T (2007) Incentive and informational properties of preference questions. Env Res Econ 37:181-210

CSIRO (2008) Regional temperature projections in Australia to 2100 for three climate cases, data prepared for the Garnaut climate change review. CSIRO, Aspendale 
CSIRO, Australian Bureau of Meteorology (2007) Climate change in Australia: technical report 2007. CSIRO

Department of Climate Change and Energy Efficiency (2008) Carbon pollution reduction scheme: Australia's Low Pollution Future, White Paper, Volume 1, December 2008. http://www. climatechange.gov.au/publications/cprs/white-paper/cprs-whitepaper.aspx

Department of Climate Change and Energy Efficiency (2010) National greenhouse gas inventory 2007-Kyoto protocol accounting framework. http://www.ageis.greenhouse.gov.au/

Garnaut R (2008) The Garnaut climate change review: final report, Commonwealth of Australia. Cambridge University Press, Melbourne

International Panel on Climate Change (IPCC) (2007) IPCC fourth assessment report: climate change 2007. http://www.ipcc.ch/pdf/assessment-report/ar4/syr/ar4_syr.pdf

Karl TR, Trenberth KE (2003) Modern global climate change. Science 302:1719-1723

Krinsky I, Robb AL (1986) On approximating the statistical properties of elasticities. Rev Econ Stat 68:715-719

Lee JJ, Cameron TA (2008) Popular support for climate change mitigation: evidence from a general population mail survey. Env Res Econ 41:223-248

Lowe T, Brown K, Dessai S, de França Doria M, Haynes K, Vincent K (2006) Does tomorrow ever come? Disaster narrative and public perceptions of climate change. Public Underst Sci 15:435457

Macmillan DC, Hanley N, Buckland S (1996) Contingent valuation of uncertain environmental gains. Scot J Polit Econ 43:519-533

Nolan JM (2010) "An Inconvenient Truth" increases knowledge, concern, and willingness to reduce greenhouse gases. Environ Behave. doi:10.1177/0013916509357696

Poe GL, Severance-Lossin EK, Welsh MP, (1994) Measuring the difference (X-Y) of simulated distributions: a convolutions approach. Am J Agric Econ 76(4):904-915

Ready R, Whitehead J, Blomquist G (1995) Contingent valuation when respondents are ambivalent. J Environ Econ Manag 29:181-197

The Commonwealth Treasury (2008) Australia's low pollution future: the economics of climate change mitigation. http://www.treasury.gov.au/lowpollutionfuture/report/downloads/ALPF_ consolidated.pdf

United Nations Framework Convention on Climate Change (UNFCCC) (2008) GHG data from UNFCCC. http://unfccc.int/ghg_data/ghg_data_unfccc/time_series_annex_i/items/3814.php

Viscusi WK, Zeckhauser RJ (2006) The perception and valuation of the risks of climate change: a rational and behavioral blend. Climatic Change 77:151-177

Wilson KM (1995) Mass media as sources of global warming knowledge. Mass Commun Review 22(1-2):75-89 